\title{
THE IMPACT OF THE COVID 19 PANDEMIC ON CANCER DIAGNOSIS IN A PATHOLOGY SERVICE IN SOUTHERN BRAZIL
}

\section{ORIGINAL ARTICLE}

KLOCK, Julia Cristhina Monteiro', Borges, Giuliano Santos², OGATA, Daniel Cury³, KLOCK, Clóvis ${ }^{4}$

KLOCK, Julia Cristhina Monteiro. Et al. The impact of the covid 19 pandemic on cancer diagnosis in a pathology service in southern Brazil. Revista Científica Multidisciplinar Núcleo do Conhecimento. Year. 06, Ed. 11, Vol. 14, pp. 182-190. November 2021. ISSN: 2448-0959, Access Link: https://www.nucleodoconhecimento.com.br/health/pathology-service, $\quad$ DOI: 10.32749/nucleodoconhecimento.com.br/health/pathology-service

\section{SUMMARY}

The Covid-19 pandemic has had a significant impact on people's lives. One of these impacts can be verified in the diagnosis of other diseases, especially cancer. Problem: What was the impact on the diagnosis of new cases of cancer in the region covered by a pathology service in southern Brazil during the pandemic? General objective: To evaluate whether there was a decrease in the number of cancer diagnoses in a pathology service in southern Brazil during the pandemic. Methodology: We analyzed the case reports carried out in the Laboratories of the Infolaudo Group, during the initial months of the pandemic (April and May 2020) and compared with the same months of 2019 , in order to measure the impact of the pandemic on the diagnosis of cancer in a Pathology Service in southern Brazil. Results: Comparing the periods of April and May 2019 with the same period in 2020, a $34.2 \%$ decrease in pathological procedures was noticed. Some types of cancer,

\footnotetext{
${ }^{1}$ Medical Student - University of Mogi das Cruzes. ORCID: 0000-0002-0834-193X.

${ }^{2}$ Specialty in Oncology, Graduation in Medicine. ORCID: 0000-0002-0737-7922.

${ }^{3}$ Doctor of Surgery, Master in Surgery, Specialty in Pathology, Graduation in Medicine. ORCID 0000-0001-88192155.

${ }^{4} \mathrm{PhD}$ student in Oncology, Specialty in Pathology, Graduation in Medicine. Orcid 0000-0001-8456-0061.
} 
such as colon, esophagus, breast and prostate, had a significant decrease in diagnoses, being $19.7 \%, 45 \%, 18.2 \%$ and $37.7 \%$, respectively. Conclusion: With the closure of many clinics and clinics in the early stages of the pandemic, there was a decrease in cancer diagnoses in the laboratories surveyed.

Keywords: Pandemic, Covid 19, cancer, pathology.

\section{INTRODUCTION}

The World Health Organization (WHO) estimates that by 2030 there will be 27 million new cases of cancer, 17 million deaths from the disease and 75 million people living with cancer around the world (INCA, 2020).

Cancer is the leading cause of death in developed and developing countries (ALLGAR and NEAL, 2005). However, certain types of cancer have a high chance of cure if they are detected at an early stage and treated appropriately (AMBUSAIDI and AL-BALUSHI, 2012).

Delays in the diagnosis of cancer can occur throughout the diagnosis, according to the levels of health care: patient, primary care and secondary care.Diagnoses in more advanced neoplastic diseases may occur when the patient is slow to recognize and act in relation to suspected symptoms (ASCO, 2020). This low awareness of early symptoms of cancer is considered the predominant reason for a late presentation, especially when the symptoms are of an atypical nature (ASCO, 2020). Another possible barrier may be related to the high demand for specialized medical services, and may eventually delay the diagnosis, especially in public services (INCA, 2020).

In Brazil, according to THE INCA, in 2020, 309,230 new cases of cancer were estimated, in men, prostate cancer was responsible for $29.2 \%$ of the estimated cases. In women, of the 316,140 new cases expected, breast cancer corresponded to $29.7 \%$. These data do not include non-melanoma skin cancer (GREEN et al., 2015). 
In a case, the delay in cancer diagnosis can occur on several levels. The patient may fail to recognize suspected symptoms of cancer or act on them. The primary care physician may not recognize patients with suspected cancer symptoms and investigate them properly or refer them in time.Patients with clinical suspicion, in secondary care, may not be seen in time or may be referred to the wrong specialty.

During the coronavirus pandemic, the preventive measures adopted, such as: social distancing and quarantine, affected the initial diagnosis of cancer patients. Thus, the overcrowding observed in several hospitals made it impossible to properly diagnose and treat these patients.

In this scenario, data from the local sample lack to verify whether the pandemic really affected this group of patients and cancer diagnoses.

In view of this, the present article has as a guide question: What was the impact on the diagnosis of new cases of cancer in the region covered by a pathology service in southern Brazil during the pandemic? With the general objective of evaluating whether there was a decrease in the number of cancer diagnoses in a pathology service in southern Brazil during the pandemic

Data from the beginning of the pandemic (April and May) of 2020 were analyzed, comparing with data from April and May 2019, from a Pathology Service of the Southern Region of Brazil (Infolaudo Group) to recognize the current situation and the impacts resulting from the lockdown period on the diagnosis of this group of individuals.

This is a cross-sectional and quantitative epidemiological study of the local sample.

\section{MATERIALS AND METHODS}

All case reports from April and May 2020 and April and May 2019 were analyzed, carried out in the Infolaudo Group Laboratories, and they were compared with each other. The periods chosen were defined due to the beginning of social isolation and lockdown measures. All patients included in this study were treated in the Foz region 
of the Itajaí River, Alto vale, greater Florianópolis and the north and west of Rio Grande do Sul (Erechim and Cruz Alta).

All cases diagnosed with cancer were included in the study. Cases that did not have confirmation of the diagnosis of cancer were excluded. The collected data were incorporated into the Microsoft Office Exce|® program 2010 and the results were presented in absolute numbers and percentages. This is a cross-sectional and quantitative epidemiological study of the local sample.

\section{DISCUSSION}

Delays in primary care may occur in the recognition, investigation and referral of cases with suspected malignant neoplasia (ASCO, 2020).Although primary care is the first point of contact for patients using national health services in several countries around the world, the delay in cancer diagnosis remains a continuous problem at this level (JONES et al., 2007).Primary care physicians are expected to identify patients with possible disease at an early stage. However, the diagnosis of cancer is relatively uncommon for the primary care physician, as more than $80 \%$ of patients have nonspecific symptoms (HARFORD, 2011).In fact, the main concern of these health professionals is to differentiate the minority of patients who need urgent attention from those who probably have self-limited conditions (KAUFMAN et al., 2020).

In May 2020, the American Society of Clinical Oncology (ASCO) published a special report recommending the postponement of any clinic visits and any cancer screening or diagnosis and staging-related procedures if this postponement does not pose a risk of disease progression or worsening of the prognosis (LONDON et al., 2020).

Some international studies show that the decrease in cancer diagnosis in the first months of the pandemic was $65.2 \%$ of new cases of cancer (LONDON et al., 2020). 
Screening of some types of cancer was impaired, with data showing that breast and colon and rectum cancer were the most affected with 89.2 and $84.5 \%$ respectively (MACLEOD et al., 2009).

In a study conducted in the United Kingdom, the lockdown caused the suspension of cancer screenings, compromising the early diagnosis of countless patients. Only of this, patients with critical and symptomatic clinical picture were directed to diagnostic intervention. Cancer records were used in the National Health Service (NHS) through a database of hospitals with patients aged 15 to 84 years, diagnosed with breast cancer (35583), colorectal (24975) and esophageal cancer (6744) in 2010 with follow-up until 2014. In patients with primary lung neoplasia (29305), 2012 was used as the year of diagnosis and 2015 as the final date of follow-up. Through a flowchart to define the pathways of cancer patients within the NHS, an estimate was made to assess the consequences of diagnostic delay in this group of patients, over a period of 12 months, starting in March 2020 (date of lockdown),contextualizing with its impact 1, 3 and 5 years after the initial diagnosis. In this methodology, three routes or flows of these patients were considered, corresponding from the best to the worst case scenario. Based on this, the actual impact of survival at 1, 3 and 5 years after diagnosis was estimated, thus calculating the total number of deaths attributed by cancer and the total number of years of life lost, comparing with pre-pandemic data.

In all scenarios, an increase of $7.9 \%$ to $9.6 \%$ of breast cancer deaths was estimated within 5 years of diagnosis, meaning 281 to 344 more deaths, respectively. In colorectal cancer, the increase was from 15.3\% (1445) to 16.6\% (1563) and in lung cancers, this increase was $4.8 \%(1235)$ to $5.3 \%$ (1372). Finally, the increase observed in patients with esophageal cancer was $5.8 \%$ (330) to $6 \%$ (342). These data show that there has been a significant increase in preventable deaths in the UK, probably due to restrictive and social isolation measures (MARINGE et al., 2020).

Another study published by Kaufman et al. (2020) observed a 40\% reduction in the weekly incidence of cancer in the Netherlands and $75 \%$ in the United Kingdom since the beginning of the covid-19 pandemic. This study used a methodology similar to ours, evaluating the records of a database from January to April 2019, compared to 
the same period of 2020. They noticed significant falls in the diagnosis of malignant neoplasms, in situ and indeterminate behavior. During the pandemic, the weekly number of cases fell by more than $46 \%$ in the six most common types of cancer, with variations of $24.7 \%$ in cases of pancreatic neoplasia and $51.8 \%$ in breast cases (WHO, 2016).

Another article, published by researchers from the Sidney Kimmel Center in Philadelphia and the NHS, showed an $89.2 \%$ reduction in breast cancer screening and $85.5 \%$ decrease in colonoscopies, which is an important tool for early diagnosis of colorectal cancer (VOSE, 2020).

All cases of the Infolaudo Group in the periods of March and April 2020 were compared with the period of March and April 2019. The months of March and April were selected, as they were the initial months of lockdown.

In 2019, in April and May, the Laboratories of the Infolaudo Group received 5524 pathological procedures, of which 4634 were benign lesions and 890 malignant lesions, representing $16.1 \%$. In 2020 , in the same period, there were 3635 procedures, with 2,875 benign lesions and 760 malignant lesions, representing malignant $20.9 \%$. There was a $34.2 \%$ decrease in pathological procedures. (Graph 1) 
Graph 1: Decrease in pathological procedures in April and May 2020 in relation to the same period of 2019.

\section{Lesões benignas X Lesões malignas}

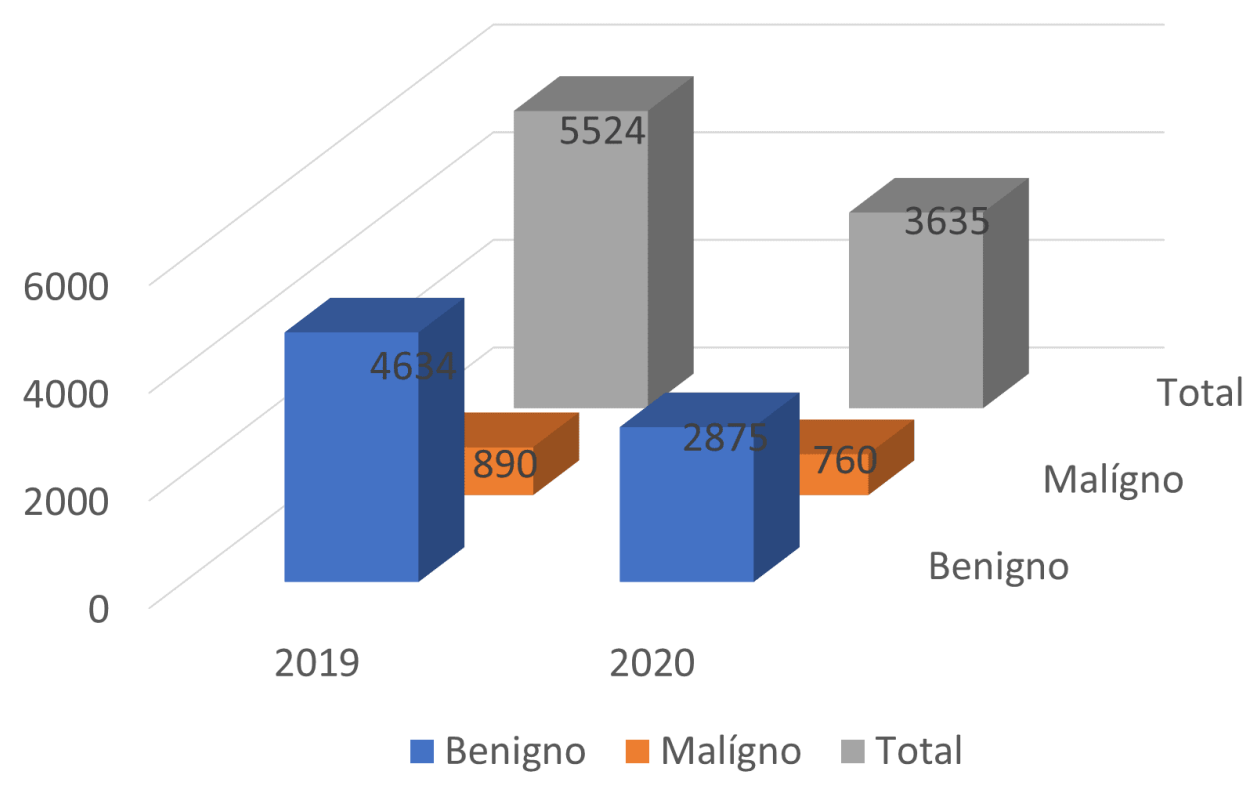

Source: authors

In general, in all different procedures, there was a decrease in diagnosis, be it biopsies or surgical specimens. Some types of procedures had a more marked decrease, such as major elective surgeries that required hospitalization of the patient.

Some types of cancer (Graph 2) had a more significant decrease, such as colon (19.7\%), esophagus (45\%), breast (18.2\%) and prostate (37.7\%). 
Graph 2: decrease in cancer diagnoses (by organs) most affected in April and May 2020 compared to the same period of 2019.

\section{TOPOGRAFIAS}

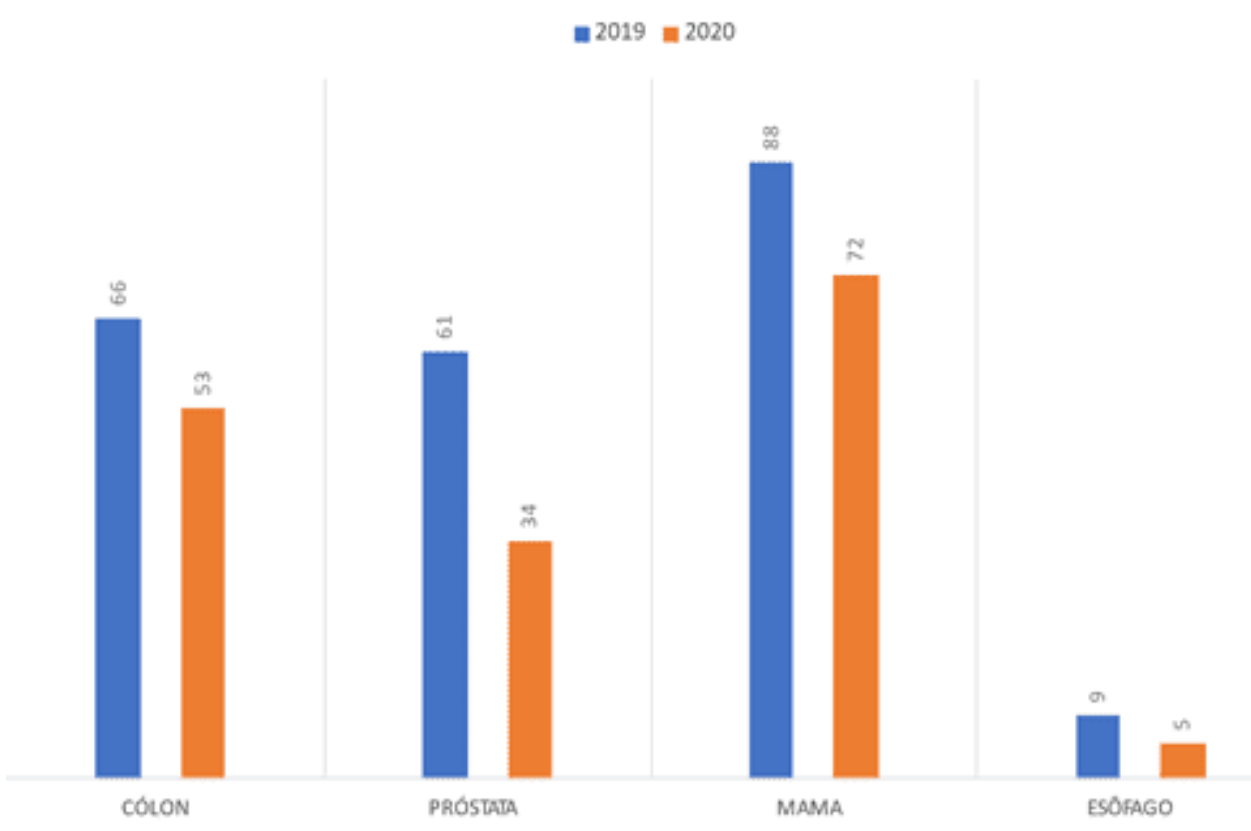

Source: authors.

The main decrease was in cases that would require some invasive procedure, and in cases of sedation of the patient. Other types, such as skin cancers, did not decrease in the same period.

The surgical blocks of most hospitals also limited elective surgeries, due to the need to leave beds vacant, especially ICU beds.

With the impact of the closure of many clinics and clinics in the early stages of the pandemic, there was a great impact on these diagnoses. In addition to the fear of patients leaving their homes, which was also one of the factors that helped in this decrease.

This study has some limitations. First, only the impact of blockade on diagnosis in a group of laboratories were evaluated, although it is a large service. The results of the 
present study, therefore, are not necessarily applicable to other centers, so multicenter studies would be necessary to validate these results on a national scale. It is possible that this induced a selection bias. However, this method of patient selection was identical for all periods studied, allowing comparability.

\section{FINAL CONSIDERATIONS}

Returning to the right question: What was the impact on the diagnosis of new cases of cancer in the region covered by a pathology service in southern Brazil during the pandemic? Through the study presented, it was possible to conclude that the data analyzed in the reports of patients seen in the Infolaudo Group showed that the diagnosis of some types of cancer decreased in the initial period of the pandemic in 2020 with the analyzed period of 2019 , showing that the pandemic affected this type of diagnosis. There was also a large decrease in the number of biopsies and surgical specimens received in the period. This explanation can be multifactorial, and may be influenced by the closure of diagnostic services such as clinics and sectors of hospitals, as well as by the fear of patients seeking medical care.

\section{REFERENCES}

ALLGAR, V. L.; NEAL, R. D. Delays in the diagnosis of six cancers: analysis of data from the National Survey of NHS Patients: Cancer. Br J Cancer, 2005.

AMBUSAIDI, A.; AL-BALUSHI, S. Educação em Saúde no Sultanato de Omã. In: Taylor, N. et al. (ed.). Educação em Saúde em Contexto. Editores Sense. 2012.

ASCO. American Society of Clinical Oncology. COVID-19 Patient Care Information. 2020. Disponível em: https://www.asco.org/asco-coronavirus-information/careindividuals-cancer-during-covid-19. Acesso em: 26 de jun. de 2020.

GREEN, T. et al. Cancer detection in primary care: insights from general practitioners. Ir. J Cancer, 2015. 
HARFORD, J. B. Breast-cancer early detection in low-income and middleincome countries: do what you can versus one size fits all. Lancet Oncol, 2011.

INCA. Instituto Nacional de Câncer. Estimativa 2020: incidência de câncer no Brasil. Rio de Janeiro: INCA, 2020.

JONES, R. et al. Alarm symptoms in early diagnosis of cancer in primary care: cohort study using General Practice Research Database. BMJ, 2007.

KAUfMAN, H. W. et al. Changes in the Number of US Patients With Newly Identified Cancer Before and During the Coronavirus Disease 2019 (COVID-19) Pandemic. JAMA Netw Open, 2020.

LONDON, J. W. et al. Effects of the COVID-19 pandemic on cancer-related patient encounters. JCO Clinical Cancer Inform, 2020.

MACLEOD, $U$. et al. Risk factors for delayed presentation and referral of symptomatic cancer: evidence for common cancers. Br J Cancer, 2009.

MARINGE, C. et al. The impact of the COVID-19 pandemic on cancer deaths due to delays in diagnosis in England, UK: a national, population-based, modelling study. Lancet Oncol, 2020.

VOSE, J. M. Delay in Cancer Screening and Diagnosis During the COVID-19 Pandemic: What Is the Cost? Oncology (Williston Park), 2020.

WHO. World Health Organization. Facts about cancer. 2016. Disponível em: www.who.int

Posted: November 2021.

Approved: November 2021. 